\title{
Acute ischemic stroke resembling Saturday night palsy
}

\author{
Acidente vascular cerebral isquêmico mimetizando a síndrome do sábado à noite \\ José Luiz Pedroso ${ }^{1,2}$, Marcos Knobel², Rodrigo Meirelles Massaud², Elias Knobel ${ }^{2}$
}

A 90-year-old man woke-up with dropped hand. Examination showed weakness in left hand: inability to extend wrist and fingers. National Institutes of Health Stroke Scale (NIHSS): zero. He had left ventricular hypokinesia. Radial neuropathy was suspected. Considering age and risk for embolism, brain MRI was performed, and disclosed minor acute ischemic stroke in left frontal cortex (Figure).
Upper extremities monoparesis rarely occur in cerebral cortex lesions, and may mimic peripheral nerve injuries ${ }^{1,2}$. Saturday night palsy is a colloquial term which describes radial nerve injuries from falling asleep with the arm under the body $^{3}$. Neurologists should be aware that cerebral cortex lesions in old patients with cardiovascular risk factors may present with motor paralysis limited to the upper extremities.
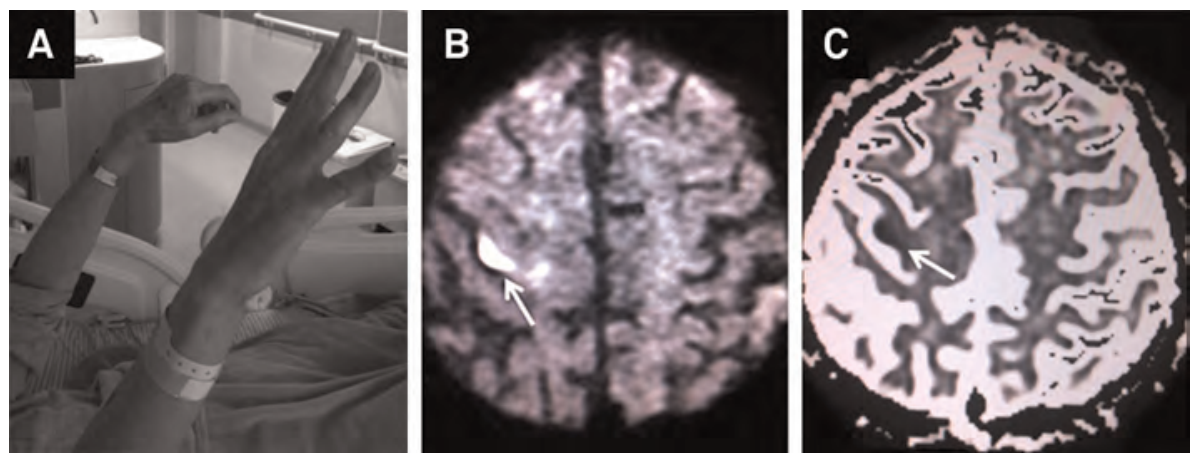

Figure. Patient with dropped hand and inability to extend left wrist, thumb and fingers (A). Diffusion-weighted brain MRI showing a small area of restricted diffusion in the left frontal cortex (B). ADC map-weighted brain MRI disclosing an hypointense signal in left frontal cortex supporting the diagnosis of acute ischemic stroke (C).

1. Edlow JA, Selim MH. Atypical presentations of acute cerebrovascular syndromes. Lancet Neurol 2011;10:550-560.

2. Takahashi N, Kawamura M, Araki S. Isolated hand palsy due to cortical infarction: localization of the motor hand area. Neurology 2002;58:1412-1414. 